\title{
Solar Water Pumping Model Using Zeta Converter for Irrigation Application
}

\author{
Vikash Kumar $^{1}$ and Amit Choudhary ${ }^{2}$ \\ ${ }^{I}$ Student, Department of Electrical Engineering, BIT Sindri, Dhanbad, India, kr.vikash104@gmail.com \\ ${ }^{2}$ Professor, Department of Electrical Engineering, BIT Sindri, Dhanbad, India, amit.ee@bitsindri.ac.in
}

*Correspondence: Vikash Kumar; Email: kr.vikash104@ gmail.com

ABSTRACT: A solar pumping model is proposed in this paper using a Brushless DC (BLDC) motor. Zeta converter is used as a DC-DC link between the voltage source inverter and the PV array. Zeta converter enables soft starting of the BLDC motor and the speed control is achieved by simple variation of DC link voltage, thereby eliminating the need for complex switching circuitry. Zeta converter belongs to the class of buck-boost converter hence offers a wide range of operating voltage. The proposed model is simple and cost-effective so it can be practically implemented with minimum cost. The proposed model is tested for its suitability in the MATLAB/Simulink environment.

Keywords: Zeta converter, PV array, solar irrigation, MPPT.

\section{ARTICLE INFORMATION \\ Author(s): Vikash Kumar and Amit Choudhary \\ Received: Nov 17, 2021; Accepted: Jan 02, 2022; Published: Jan 30, 2022; e-ISSN: 2347-470X; \\ Paper Id: IJEER-090309; \\ Citation: doi.org/10.37391/IJEER.090309 \\ Webpage-link: \\ https://ijeer.forexjournal.co.in/archive/volume-9/ijeer-090309.html}

\section{INTRODUCTION}

The consumption of electricity has increased exponentially in the past few decades. It has increased the pressure on nonrenewable fossil reserves all around the world. The pollution level has increased to its peak. Electricity is an essential component for the growth and development of a nation. A country like India where the majority of the population depends on the agricultural sector usually faces the issue of frequent power cuts or power failure. Most of the power is being diverted to the industries and cities.

The use of solar energy can prove to be a suitable and sustainable solution to this problem. Solar energy is the cleanest and most abundant green energy available around the world.[1] The initial installation cost is however high but in the long run, it becomes economical as it has zero running charges and minimum maintenance cost. Indian farmers can be benefitted from the implementation of solar irrigation structures. It would ensure a continuous supply of water for the crops and the elimination of electricity bills.

The proposed PV solar irrigation system uses a centrifugal pump coupled to a BLDC motor fed by a DC-DC Zeta converter.[2] The rugged performance characteristics of the BLDC motor such as high efficiency, reliability, easy and smooth speed control, high torque to inertia ratio and negligible maintenance makes it a suitable choice for the pumping application.[3] Zeta converter serves several advantages over other DC-DC converters which makes it a suitable choice. The Zeta converter is a buck-boost converter hence offers a wide range of operating voltage for the application. This feature is exploited for the smooth starting of the BLDC motor. [4] This converter topology has an inductor at its output terminal which makes the output current smooth and ripple-free. It has minimum switches hence the switching losses are minimum and operates in the continuous conduction mode. Zeta converter unlike other buck-boost converters does not operate in the inverting mode i.e., the output voltage never changes its polarity. This reduces the need for additional circuitry and reduces the complexity of the circuit [5]. To ensure that the system operates at peak power MPPT technique using Perturb and Observe algorithm is used.

\section{SYSTEM CONFIGURATION AND OPERATION}

The proposed system broadly has the following major parts i.e., PV array, Zeta converter, Voltage Source Inverter, BLDC motor with an inbuilt encoder coupled with the centrifugal pump. The proposed prototype with major blocks is depicted in figure 1.

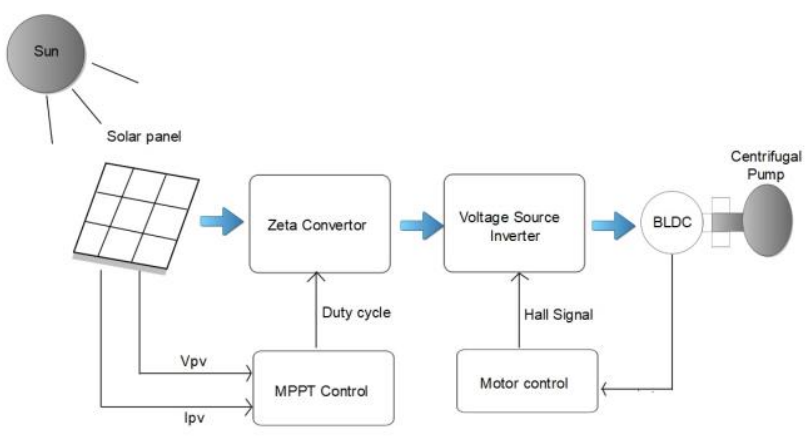

Figure 1: Prototype of the solar pumping model.

The PV array generates the electrical energy (which depends on the amount of irradiance and atmospheric temperature) is fed directly to the Zeta converter. This energy is then forwarded to VSI with minimum possible losses as the converter has only one switching part.[2] The voltage at the output remains fairly constant. To ensure that the maximum 
power is extracted from the PV array MPPT technique is used. The Perturb and Observe algorithm uses voltage and power as the input to generate the duty cycle, which in turn is fed to the pulse generator. The switching pulses are generated to control the MOSFET (Metal Oxide Semiconductor Field Effect Transistor) of the converter. The VSI converts the input DC into $\mathrm{AC}$ and feeds the motor-pump combination.[6] The inbuilt encoder in the BLDC motor generates the switching signal for the VSI. This ensures switching at the fundamental frequency which reduces the switching losses thereby enhancing the efficiency of the system.[7]

\section{DESIGN OF PROPOSED TOPOLOGY}

The pumping topology is designed with the specification such that it fulfils the need of irrigation application. The power of the BLDC motor used is $2 \mathrm{KW}$ and that of a centrifugal pump is $1.5 \mathrm{KW}$. The other sub-stages of the system are designed such that it meets the power requirement of the motor-pump combination.

\subsection{Design of PV array}

The solar panel contains a network of photovoltaic cells connected in series and parallel fashion. PV cell is a non-linear device as its purely made up of semi-conductor elements such as silicon and germanium. The electrical model of the PV cell is shown in figure 2 .

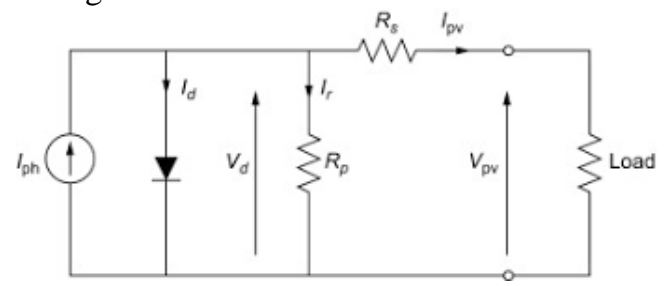

Figure 2: Electrical model of solar cell

The set of equations governing the current produced by the above electrical model is given as

$$
\begin{aligned}
& i=i_{n}-i_{r}-i_{e} \\
& i=i_{n}-i_{s}\left[\exp \left(\frac{v+i \cdot r_{e}}{v_{t}}\right)-1\right]-\left[\frac{v+i \cdot r_{e}}{r_{h}}\right]
\end{aligned}
$$

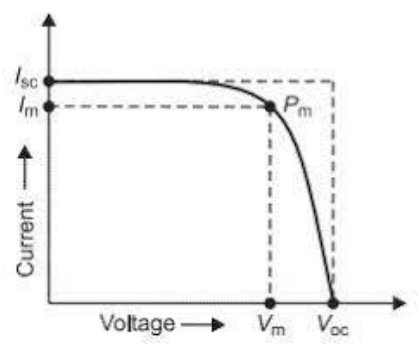

Figure 3: I-V Characteristics of solar cell

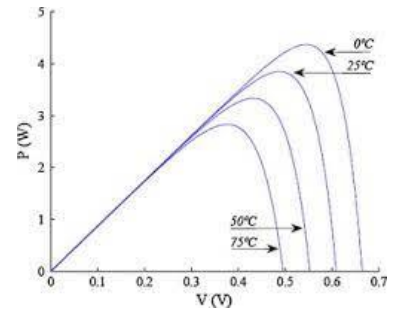

Figure 4: P-V Characterstics of solar cell

Here, is insolation current, is reverse saturation current, is cell voltage and is the thermal voltage which depends on temperature. Hence the performance of PV cells mainly depends on two factors, temperature and solar irradiance. This is shown in Figures 3 and 4.

The PV array with a power rating of $2 \mathrm{KW}$ is chosen. The open-circuit voltage and short circuit current are 36.3 volts and 7.84 amps respectively. However, the peak value of voltage and current is 29 volts and 7.35 amps. The required PV voltage is assumed to be 180 volts. The no of modules to be connected in series and parallel for the required power is evaluated below.

The modules to be connected in parallel is:

$n_{p}=\frac{v_{p v}}{v_{m}}=\frac{180}{29}=6.20 \sim 6$

Number of panels connected in series is:

$i_{p v}=\frac{p_{p v}}{v_{p v}}=\frac{2000}{180}=11.11$

$n_{s}=\frac{i_{p v}}{i_{m}}=\frac{11.11}{7.35}=1.51 \sim 2$

Table 1. PV panel specifications

\begin{tabular}{|l|c|}
\hline Rated power of PV panel (Watts) & 213 \\
\hline Open circuit voltage (volts) & 36.3 \\
\hline Short circuit current (amps) & 7.84 \\
\hline Peak voltage (volts) & 29 \\
\hline Peak current (amps) & 7.35 \\
\hline Module in series $\left(n_{s}\right)$ & 2 \\
\hline Module in parallel $\left(n_{p}\right)$ & 6 \\
\hline
\end{tabular}

\subsection{Evaluation of ZETA converter}

Zeta converter is a fourth-order DC-DC converter having two inductors and two capacitors. It has only one switch which makes its switching losses negligible. Usually, Zeta converters are used for power applications below $5 \mathrm{KW}$. The electrical circuit of the converter is shown in figure 5 .

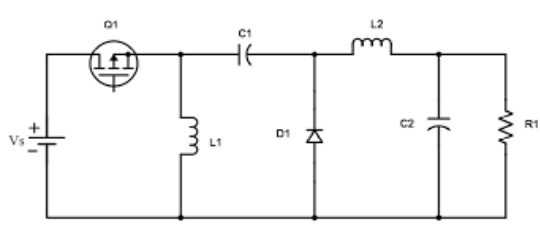

Figure 5: Electrical model of ZETA converter 
The major components of the converter are two inductors $1_{1}, 1_{2}$ two capacitors $c_{1}, c_{2}$. The values of these inductors and capacitors are evaluated such that the complete system operates in the continuous conduction mode. The output voltage of the converter vdc is desired as 210 volts. When the solar panel operates under the normal specified condition it produces around 180 volts. Based on these values the duty cycle is obtained as:

$d=\left[\frac{v_{d c}}{v_{d c}+v_{m}}\right]=\left[\frac{210}{210+180}\right]=0.538$

The DC current flowing through the converter is

$i_{d c}=\left[\frac{p_{m}}{v_{d r}}\right]=\left[\frac{2000}{210}\right]=9.52$

The other components are evaluated based on the duty cycle and the DC current.

Table 2. Parameters of ZETA converter

\begin{tabular}{|c|c|c|}
\hline Component & Governing equation & $\begin{array}{c}\text { Parameter } \\
\text { value }\end{array}$ \\
\hline $\mathrm{L}_{1}$ & {$\left[\frac{d * v_{m}}{f_{w} * \Delta i_{l 1}}\right]=\left[\frac{0.538 * 180}{20000 * 11.11 * 0.1}\right]$} & $4.53 \mathrm{mH}$ \\
\hline $\mathrm{L}_{2}$ & {$\left[\frac{(1-d) * v_{d c}}{f_{w} * \Delta i_{l 2}}\right]=\left[\frac{(1-0.538) * 210}{20000 * 9.52 * 0.1}\right]$} & $5.09 \mathrm{mH}$ \\
\hline $\mathrm{C}_{1}$ & {$\left[\frac{d * i_{d c}}{f_{w} * \Delta v_{c 1}}\right]=\left[\frac{0.538 * 9.52}{20000 * 210 * 0.1}\right]$} & $12.19 \mu \mathrm{F}$ \\
\hline $\mathrm{C}_{2}$ & {$\left[\frac{i_{d c}}{6 * w_{l} * \Delta v_{d c}}\right]=\left[\frac{9.52}{6 * 376.991 * 210 * 0.1}\right]$} & $200.141 \mu$ \\
\hline
\end{tabular}

Here, $l_{1}$ is the input inductor, $l_{2}$ is the output inductor, $\Delta f_{w}$ is the switching frequency of the MOSFET. $\Delta \mathrm{i}_{1}$ is the allowed ripple content in the input current. $\Delta \mathrm{i}_{2}$ is the ripple current in the output. $\mathrm{C}_{2}$ is the DC link capacitor which is estimated based on the upper and lower speed of the motor which is taken as $3000 \mathrm{rpm}$ and $1200 \mathrm{rpm}$.

\subsection{Design of motor pump system}

The BLDC motor of $2 \mathrm{KW}$ rating with 6 poles and $3000 \mathrm{rpm}$ rating is selected. The torque-speed characteristics are used to evaluate the motor constant.

$$
a_{k}=\left(\frac{t_{l}}{w_{m}^{2}}\right)=\left(\frac{5.05}{(2 * \pi * 3000) / 60)^{2}}\right)=5.116 * 10^{-5} \mathrm{Nm} /(\mathrm{rad} / \mathrm{sec})^{2}
$$

Where $a_{k}$ is the inertia constant of the pump, $t_{l}$ is the rated load torque required and $w_{m}$ is the mechanical speed of the motor. The centrifugal pump is connected to the reservoir model which serves the purpose of a well or water source and the output discharge is connected to a constant pressure tank that estimates the volume of water discharged.

\subsection{MPPT control technique}

MPPT technique ensures that maximum power is generated by the PV panel that can be utilized by the system. Perturb and Observe algorithm used closely monitors the variation in output voltage and the corresponding power through a loop mechanism.[2] The present instantaneous power is compared with the previous based on which the duty cycle is increased or decreased. If the power increases duty cycle remains in its previous state however if the power decreases the control mechanism reverses.

\section{SIMULATION AND RESULTS}

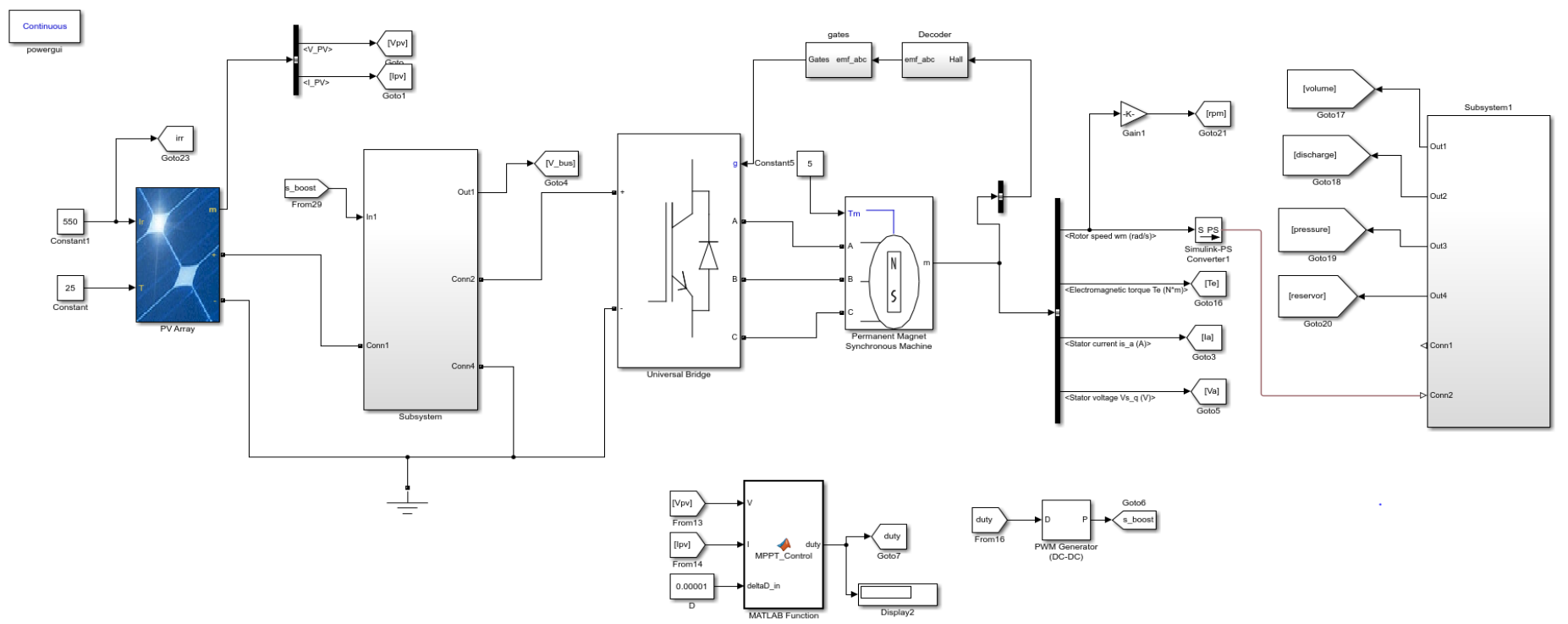

Figure 6: Simulink model of solar pumping system 
The complete Simulink model of the system is shown in the figure 6. The two subsystems which are zeta converter block and centrifugal pump block is shown in the figure 7 and 8 .

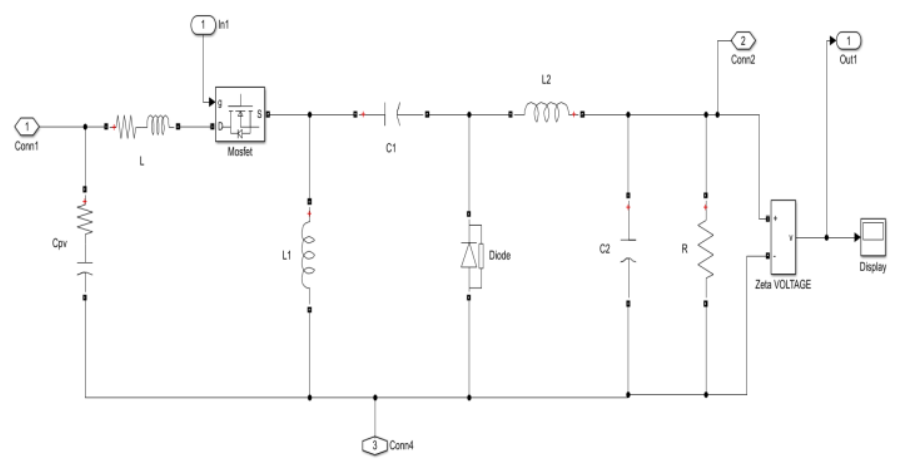

Figure 7: Simulink model of Zeta converter

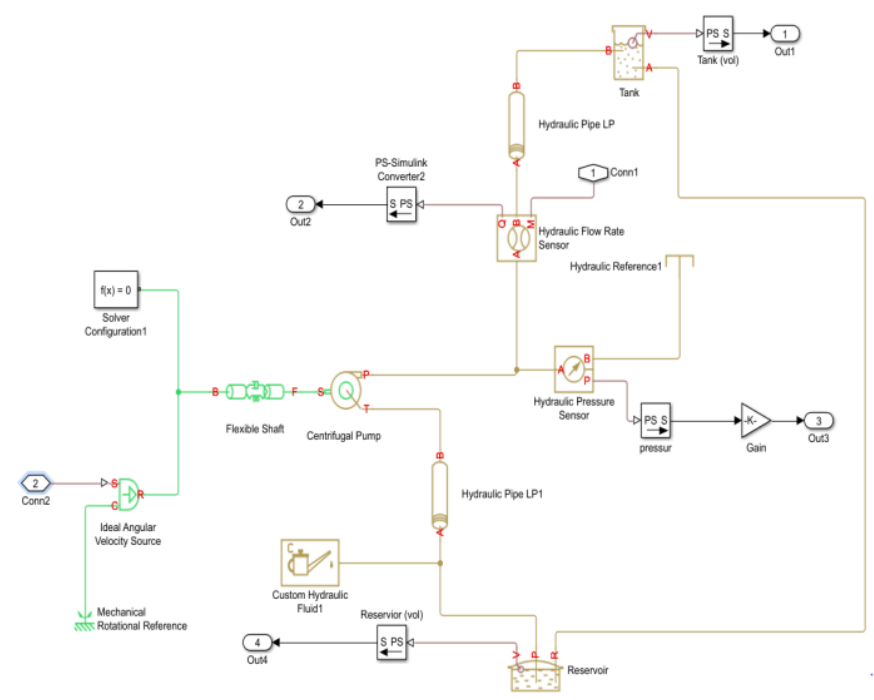

Figure 8: Simulink model of water pumping block

The parameters of the PV panel such as voltage, current and power levels obtained by varying the irradiance level from $950 \mathrm{~W} / \mathrm{m} 2$ to $550 \mathrm{~W} / \mathrm{m} 2$ has been plotted in figure 9 .
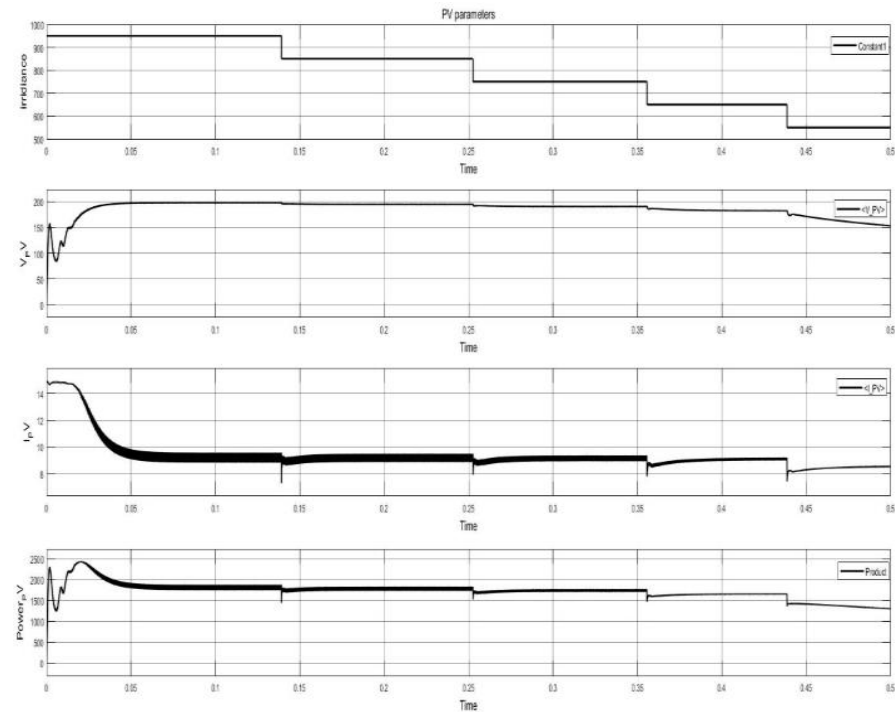

Figure 9: Output parameter of PV panel
The output voltage varies from around 200 volts to around 160 volts. Similarly, the power varies from rated $2000 \mathrm{~W}$ to $1500 \mathrm{~W}$. The variation of current is high at the initial stage due to the uncharged capacitor, however, in a very short duration, the current achieves the steady value of 9 ampere.

The Zeta converter is designed such that the output remains constant at around 210 volts. However, due to losses across resistor and diode, it remains constant at around 200 volts. The variation in output voltage is very minimal thus making it a suitable choice for the irrigation application.

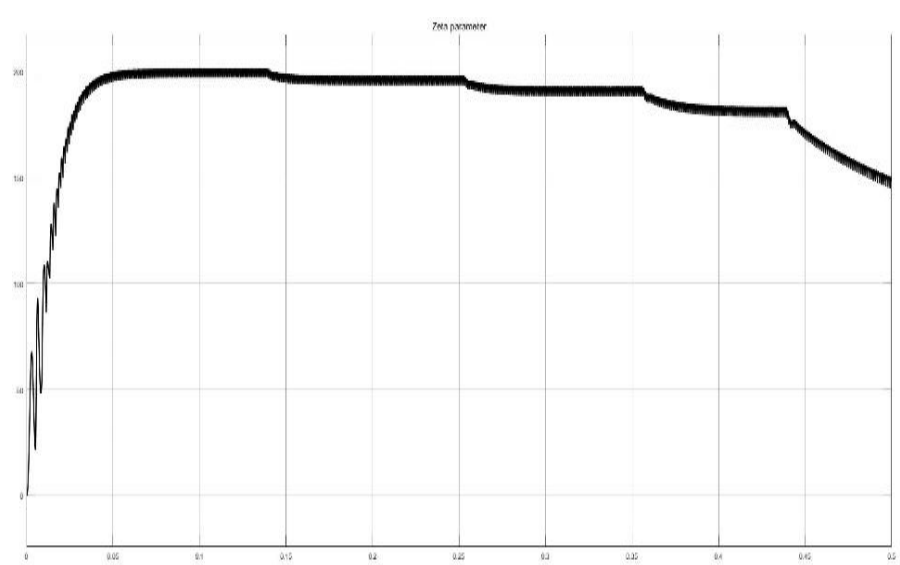

Figure 10: ZETA converter topology
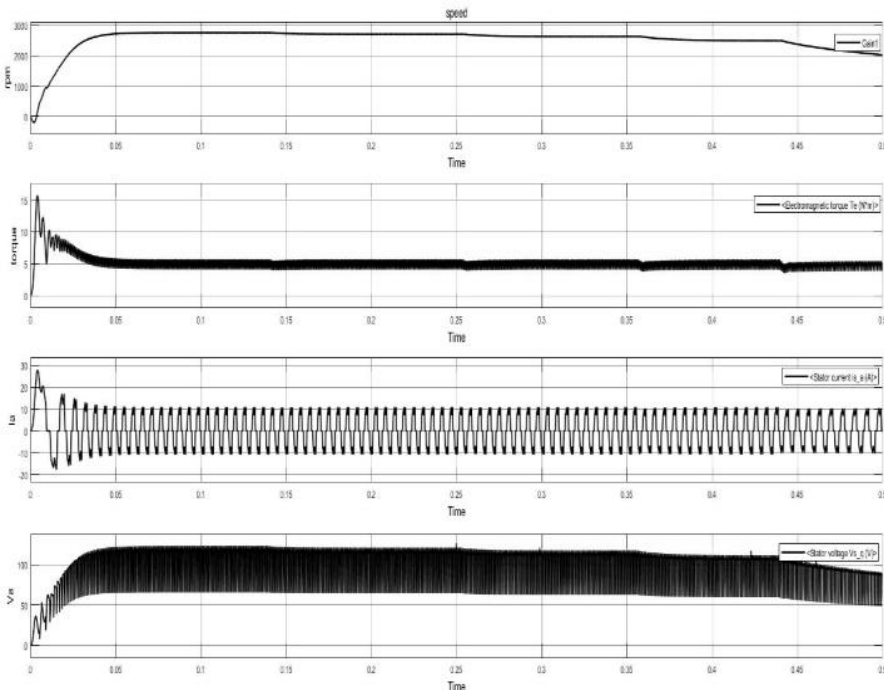

Figure 11: Parameters of BLDC motor

The output of the Zeta converter is given to VSI which converts the DC voltage into three-phase AC and then feeds it to the BLDC motor. The parameters of the motor are plotted against the variation in irradiance level. The speed remains fairly constant around $3000 \mathrm{rpm}$. The torque is around $5 \mathrm{Nm}$. 


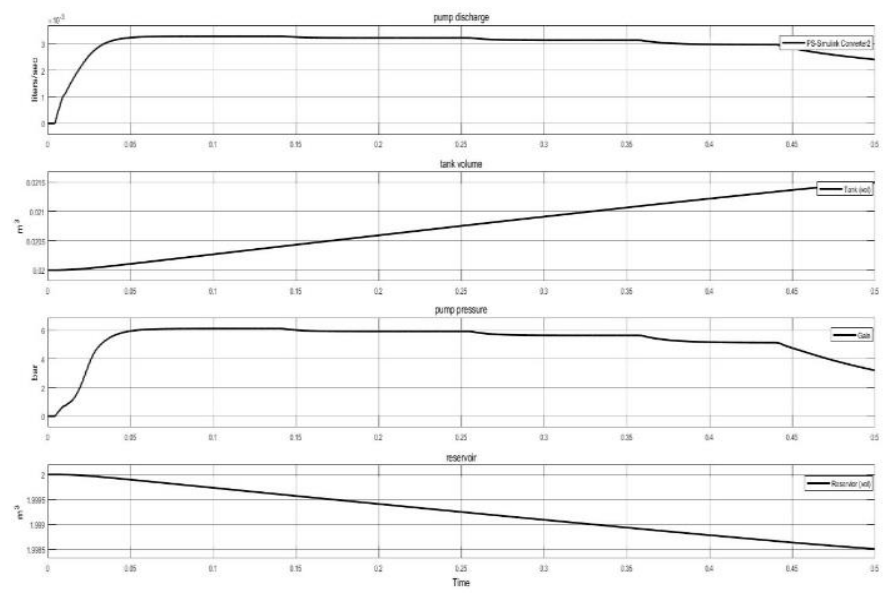

Figure 12: Parameters of centrifugal pump

The centrifugal pump connected to the BLDC motor runs at the rated speed of $3000 \mathrm{rpm}$ and pumps water from the reservoir which models a well. The discharge is stable at around 3 to 3.5 liters per second. All the important output parameters of the system are tabulated in the table 3.

Table 3. Output performance parameters of system

\begin{tabular}{|c|c|c|c|c|c|c|}
\hline Irradiance & Vpv & Ipv & Ppv & rpm & discharge & $\begin{array}{c}\text { Zeta } \\
\text { voltage }\end{array}$ \\
\hline (W/m $)$ & (volts) & $(\mathbf{a m p s})$ & $(\mathbf{K W})$ & & $(\mathbf{L} / \mathbf{s e c})$ & (volts) \\
\hline 950 & 197.7 & 9.188 & 1.916 & 2751 & 3.28 & 201.1 \\
\hline 850 & 194.6 & 9.177 & 1.787 & 2713 & 3.23 & 198.4 \\
\hline 750 & 191.2 & 8.973 & 1.715 & 2641 & 3.15 & 193.0 \\
\hline 650 & 183.5 & 8.942 & 1.641 & 2552 & 3.03 & 185.0 \\
\hline 550 & 146.5 & 8.542 & 1.251 & 1992 & 2.73 & 148.8 \\
\hline
\end{tabular}

\section{CONCLUSION}

The proposed solar water pumping model for irrigation purposes using Zeta converter is designed and its suitability has been tested for the desired application. The model is suitable for irrigation purposes at a smaller scale which is suitable of small and marginal farmers. The performance of the system can further be improved by using filters to reduce the ripple content present in the output voltage of the converter.

The proposed system is very useful for other low power applications. As the converter gives a constant output voltage, similar model can be used for building PV based charging units for small electric vehicles, it can also be used in the design of power units of street lamps in rural areas.

\section{REFERENCES}

[1] R. Nisha and K. Gnana Sheela, "Review of PV fed water pumping systems using BLDC Motor," Materials Today: Proceedings, vol. 24, pp. 1874-1881, 2020, doi: 10.1016/j.matpr.2020.03.612.

[2] S. Saravanan and N. R. Babu, "A modified high step-up nonisolated DC-DC converter for PV application," Journal of Applied Research and Technology, vol. 15, no. 3, pp. 242-249, Jun. 2017, doi: 10.1016/j.jart.2016.12.008.

[3] N. Priyadarshi, M. S. Bhaskar, S. Padmanaban, F. Blaabjerg, and F. Azam, "New CUK-SEPIC converter based photovoltaic power system with hybrid GSA-PSO algorithm employing MPPT for water pumping applications," IET power electron., vol. 13 , no. 13 , pp. 2824-2830, Oct. 2020, doi: 10.1049/ietpel.2019.1154.

[4] P. Scholar, "Solar Water Pumping System Employing ZETA Converter and BLDC Motor," vol. 5, no. 2, p. 8, 2017.

[5] R. Kumar and B. Singh, "BLDC Motor-Driven Solar PV ArrayFed Water Pumping System Employing Zeta Converter", IEEE Trans. on Ind. Applicat., vol. 52, no. 3, pp. 2315-2322, May 2016, doi: 10.1109/TIA.2016.2522943.

[6] A. K. Mishra and B. Singh, "Modified SEPIC Converter Utilizing an Improved P\&O Algorithm for Design of Low Cost and Efficient Solar Energized Water Pump," in 2018 IEEE Industry Applications Society Annual Meeting (IAS), Portland, OR, Sep. 2018, pp. 1-8. doi: 10.1109/IAS.2018.8544680.

[7] A. Cordeiro et al., "Hybrid Sepic-Cuk DC-DC Converter Associated to a SRM Drive for a Solar PV Powered Water Pumping System," in 2019 8th International Conference on Renewable Energy Research and Applications (ICRERA), Brasov, Romania, Nov. 2019, pp. 169-174. doi: 10.1109/ICRERA47325.2019.8996941.

[8] Acharya UR, Joseph KP, Kannathal N, Lim CM, Suri JS (2006) Heart rate variability: a review. Med Biol Eng Comput 44(12):1031-1051

[9] Bailón R, Mainardi L, Orini M, Sörnmo L, Laguna P (2010) Analysis of heart rate variability during exercise stress testing using respiratory information. Biomed Signal Process Control 5(4):299-310

[10] Mateo J, Laguna P (2003) Analysis of heart rate variability in the presence of ectopic beats using the heart timing signal. IEEE Trans Biomed Eng 50(3):334-343

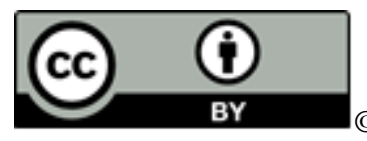

2021 by the Vikash Kumar and Amit Choudhary. Submitted for possible open access publication under the terms and conditions of the Creative Commons Attribution (CC BY) license 